at least aims of a high and noble character-aims which could not fail to have an elevating effect on those by whom they were entertained. In former times to have taken a degree in arts, as a necessary preliminary to the beginning of a student's purely professional career, may not have meant, and, as a matter of fact, did not in the majority of cases mean, any very high standard of learning or culture. It did, however, carry with it some inestimable advantages which can never be attained under the existing system of specialization. It meant that a young man, while his mind was still plastic to all surrounding influences, was brought into contact with and joined in the same pursuits as fellowstudents whose tastes would lead them to different pleasures, and whose circumstances would lead them to a variety of destinations. The plyysician or surgeon of the future became the companion of those who were afterward; to become clergymen, barristers, or schoolmasters. He read the same books, played the same games, belonged to the same clubs. In this way, how. ever little actual knowledge he may have acquired, he gained an invaluable acquaintance with men's lives and habits. He formed friendships with men destined to follow very different careers. These associations could not fail to be of the greatest value to him in the pursuit of his special profession. I do not mean mere monetary advantage, but that derived from intercourse with men in other walks of life--that interchange of ideas so neces:ary to a healthy mind. Such a training must have been beneficial to all, but to the student of medicine it was an incalculable boon. Much of his success and much of the good he can hope to do depend on an intimate knowledge of mankind. Without that, no matter how highly trained he may be as a man of science, his acquirements will be of little avail, and his skill can never be used to the highest purpose.

How is the existing system likely to work in this direction? The student is advised and encouraged to enter at once on his special pursuits. He is to apply himself without delay to scientific study, associated with men like himself, plodding along the same track. If he aims at taking honours in natural science, he must curtail his exercise to the limits of a short "constitutional" and cut himself off from the common pleasures of the cricket field and the river. His very social gatherings tend to consist. more and more exclusively of men working in his own department. The Union and other such Clubs are given up for scientific Societies, where he thinks he can combine business with amusement. Such a life can hardly fail to narrow the most sympathetic mind, to hamper and confine the most commanding intellect; it is most unlikely to turn out a practitioner of the highest and most useful type. To live in a clique where priggishness is fostered by the worst kind of mutual admiration is hardly the icleal of University education. Fortunately the curriculum indicated in the pamphlet to which I have referred is not compulsory, and an intending medical student might not be altogether unwise if he decided to pass the first three years of his career in the ordinary pursuits of the University before turning his attention to more technical studies. Even the delay of a year or two would be more than counterbalanced to some by the benefits which such a course would undoubtedly confer.

Oxford.

GEORGE I. WILSON.

\section{Migration of Swallows along the Southern Coast.}

THE following notes were made by me during a short stay at Lulworth, twelve miles east of Weymouth, from September I6 to 26 . They may be of interest to some of your readers, as I have not been able to find the facts I observed recorded in any work on British birds.

When I arrived at Lulworth on the $\mathbf{I} 6 \mathrm{th}$, swallows and housemartins were about, but in no great numbers. On the 19 th, in the course of a walk, I observed a few swallows apparently moving eastwards ; and this caused me to spend the next morning on the top of a high and narrow ridge of down (Bindon Hill), ranning parallel with the sea-an adriirable position for observation, as the movements of all birds were discernible from it at a long distance. The wind was east-north-east, and the air cold and very clear.

In half-an-hour it became clear to me that a general migration of swallows and martins was taking place alon 9 the coast in an easterly direction. The air would be thick with birds over my head for two or three minutes; then for a considerable interval hardly a bird would be visible. An ordinary glance at these dense parties was not enough to prove that they were travelling, or to show in which direction they were going ; but by keeping the eye steadily upon them for some little time, and bringing the field-glass to bear on them when the eye failed, it became obvious that they were going east at a steady rate of speed, and apparently following the long spine of chalk down on which $I$ stood, which extends from near Weymouth as far as Poole Harbour. The migration on this large scale lasted during the whole of that morning; in the afternoon the parties did not seem so large.

The next day (the 2 Ist) a strong east wind was blowing, and the birds were not travelling high in air, but creeping steadily along the flanks of the down, and on the lower ground north and south of it. They were continually tacking, but every individual that I followed with my glass was moving swiftly towards the east. Those that were on the southern or seaward side of the down would come upon the sea at one point where the coast turns sharply northwards for a short distance : they did not attempt, however, to leave the land, but turned northwards with the coast, and pursued their way along the heights. On the 2 2nd and 23 rd the same thing went on, but the numbers of the birds seemed to diminish, and they no longer went in parties that were plainly discernible. All this time there were a very few stationary swallows in one or two warm corners by the seaside.

From Dorset I went to Devonshire on the 26th. At Crediton and at Bideford (both warm and sheltered towns), I did not see a dozen swallows or martins in the course of a week; but $I$ learnt that they had gathered for departure a few days before. I have since been informed that the gatherings had been noticed in Cornwall in the first week of the month. I infer that the migration I saw at Lulw rrth was that of the extreme West of England birds, who were proceeding along the coast to the point at which they cros; the Channel. I should be glad to know where that point is.

I had reason to believe that one or two other species were moving up regularly in the same direction. The well-known migration of the pied wagtail was apparently over; but the large number of gray wagtails in a district almost destitute of water was very striking, and, as far as I could see, these also were passing eastwards. But I hope to make further observations next year.

I may add that, on returning to my home in Oxfordshire in the first week of October, I found swallows and martins passing over my village in parties during the earlier hours of each day ; but, owing to the want of a convenient elevated position for watching, it was much more difficult to fo'low their movements than it had been at Lulworth.

W. WARDE FOWLER.

\section{Swifts.}

THOUGH I cannot add anything to the interesting and valuable evidence given by your correspondent, in your last issue, with regard to swifts remaining on the wing during the dark hours of a summer night, it reminds me of a most beautiful exhibition of their flight which I witnessed at Moscow this last summer. It was on August 2, as the last rays of the setting sun were lighting up the domes and cupolas of that wonderful city, which we gazed upon from the heights of the Kremlin for the first time, that we noticed hundreds of these birds wheeling round their summits or darting hither and thither in every direction. At the same time the matchless Russian bell; were pealing forth from every bell-tower in honour of the Empress's birthday, which was to be celebrated on the morrow, and it was surely difficult to believe that the swifts were not revelling in the music like ourselves, especially as I cannot remember ever seeing them again in such numbers, though our visit to Moscow was prolonged for ten days, and we frequentiy visited the Kremlin at the same hour.

Further Barton, Cirencester, October 29.

\section{Hughes's Induction Balance.}

THE points noted by Mr. Cook on page 605 (vol. xxxvi.), are merely the well-known facts that a magnetic body has most effect when presented to the coils end-ways, i.e. with its greatest dimension along their axis, whereas a substance which acts mainly by conduction has most effect when presented flat-ways, or parallel to their face. Any possible effect due to diamagnetism is far too small to be thus easily noticed. OLIVER J. LODGE. 